oxidase inhibitors. A recent review ${ }^{4}$ confirms the existence of such patients but urges that they should be included in the same category as depressive disorder-especially now that the American Psychiatric Association uses "atypical depression" as a residual category. ${ }^{2}$

In practical terms, symptom profiles can be more useful in predicting response to monoamine oxidase inhibitors. "Nonendogenicity" is the salient feature. Responders tend to be women more than men and under the age of 40 , mood is depressed but retains its reactivity, somatic anxiety features are common, and psychomotor retardation is absent. The patients have lost interest and energy, then show irritability and hypersomnia or initial rather than late insomnia, they have evening worsening of mood, and often they overeat. They do not show guilt, delusional ideas, severe loss of weight, or suicidal intent, and these patients are not usually admitted to hospital. In one subgroup the prominent features are phobias, panic attacks, and depersonalisation.

Clearly these characteristics of the group of patients responsive to monoamine oxidase inhibitors place them at the end of any endogenous-neurotic continuum. The danger is that all that is not psychotic will be treated with these drugs. Careful selection and matching of drug. and patient profiles. are important if treatment is to be successful.

One further question remains. Even if a group of responders to monoamine oxidase inhibitors can be identified, given that the risk of suicide or hospital admission is low and that disability tends to be a result of chronicity rather than of severity, should these dangerous drugs be used? A formidable list of food and drug incompatibilities must be provided for the patient, and foods with a high tyramine content must be avoided even if these produce no symptoms. ${ }^{7}$ The risk of hypertensive crisis is five times higher with tranylcypromine than with phenelzine, and since tranylcypromine is partly metabolised to amphetamine it should never be followed by another monoamine oxidase inhibitor without a washout period.

Given reasonable caution, however, the risk of serious side effects is low, so that the use of monoamine oxidase inhibitor drugs is justifiable in patients with substantial disability who fulfil the diagnostic criteria. Recent work ${ }^{8}$ suggests that the simultaneous prescription of amitriptyline may significantly reduce sensitivity to tyramine, and such combined antidepressant treatment may prove both safe and effective in patients otherwise resistant to treatment.

\section{SYDNEY BRANDON}

Professor of Psychiatry,

University of Leicester,

Leicester Royal Infirmary,

Leicester LE2 7LX

1 World Health Organisation. Mental disorders. In: International classification of diseases. 9th revision, 1975. Geneva: WHO, 1978.

2 American Psychiatric Association. Diagnostic and statistical manual of mental disorders. 3rd edn. Washington DC: American Psychiatric Association, 1980

${ }^{3}$ Andreason NC. Concepts, diagnosis and classification. In: Paykel ES, ed. Handbook of affective disorders. Edinburgh: Churchill Livingstone, 1982: 24-44.

4 Davidson JRT, Miller RD, Turnbull CD, Sullivan JL. Atypical depression. Arch Gen Psychiatry 1982;39:527-34.

5 Anonymous. The new psychiatry. Br Med F 1981 ;283:513-4.

6 West ED, Dally PJ. Effects of iproniazid in depressive syndromes. Br Med 7 $1959 ; \mathrm{i}: 1491-4$.

7 Nies A, Robinson DS. Monoamine oxidase inhibitors. In: Paykel ES, ed. Handbook of affective disorders. Edinburgh: Churchill Livingstone, 1982 246-61.

${ }^{8}$ Pare CMB, Kline N, Hallstrom C, Cooper TB. Will amitriptyline prevent the "cheese" reaction of monoamine-oxidase inhibitors? Lancet 1982; ii:183-6.

\section{Haematuria and exercise- related haematuria}

In clinical practice microscopic and macroscopic haematuria are regarded as evidence of underlying urinary tract disease until proved otherwise. ${ }^{1}$ The standard advice is that no matter how trivial the bleeding a complete investigation is mandatory. ${ }^{2}$ Investigation may include a formidable array of invasive procedures such as intravenous and perhaps retrograde pyelography, cystoscopy, renal biopsy, and renal arteriography.

Behind this aggressive policy lies the fear of missing a malignant lesion. Since, however, the routine use of dipstick methods has increased the frequency of detection of microscopic haematuria, we need fresh guidance in selecting patients for full investigation. One particular current problem is the number of athletes who develop transient haematuria after running long distances. Glomerulonephritis, present in some $1 \%$ of the community, is probably the most frequent cause of asymptomatic haematuria. By contrast, only about one in 10000 people in middle age have tumours of the bladder and kidney. ${ }^{34}$ The prevalence of microscopic haematuria has been documented better in children than in adults. One of the best studies reported microscopic haematuria in $4 \%$ of children. Renal biopsies were done in 23 of the 27 children in whom microscopic haematuria persisted, and 13 were found to have clinically significant lesions. ${ }^{5}$ Larcom and Carter ${ }^{6}$ found more than two erythrocytes per high-power field in $1.2 \%$ of 3000 young men, and a study from Singapore reported more than five erythrocytes per high-power field in $1.5 \%$ of 67695 Army recruits. ${ }^{7}$ This study emphasised the frequency of glomerulonephritis, which was detected in $93 \%$ of the 121 recruits who consented to renal biopsy. Eight of these developed renal failure in only three years-glomerulonephritis may prove as "malignant" as cancer. ${ }^{8}$

In 1979 Birch and Fairley ${ }^{9}$ described a method for examining erythrocytes in the urine and differentiating those coming from the glomerulus from those produced by non-glomerular disease. More recently, they have illustrated the changes in more detail ${ }^{10}$ and carried out a blind evaluation of urine findings in 112 patients with haematuria. ${ }^{11}$ This analysis shows a high degree of sensitivity $(99 \%)$ and specificity (93\%) for diagnosing glomerular bleeding. In non-glomerular bleeding the sensitivity of the test was $100 \%$ and the specificity $90 \%$; in other words, no tumours would have been missed.

These studies show that simple observations of the morphological features of erythrocytes in urine permit the expert to diagnose the site of urinary bleeding with a high degree of accuracy. One of the beauties of the method is its simplicity. It requires only a urine specimen, a phase-contrast microscope, and a counting chamber, and must be preferred to invasive procedures claimed to distinguish upper-tract from lowertract bleeding. ${ }^{12}$ Erythrocytes that arise from glomeruli show great variation in size, shape, and haemoglobin content, whereas those coming from lesions such as infection, calculi, tumours, and other non-glomerular sources are uniform in size and shape and usually retain a high haemoglobin content (except when the urine is strongly acid).

It is surprising that the importance of these changes has been overlooked for so long. Addis noted fragmented and partially lysed cells but did not conclude that such cells indicated a glomerular lesion. ${ }^{1314}$ Larcom and Carter ${ }^{6}$ stained fragmented cells to define.them better but also failed to recognise their significance. The crucial innovation may have been the recognition that phase-contrast microscopy is 
essential for accurate evaluation of the variation in red-cell morphology which accompaniès glomerular bleeding. If this method is to become an important part of clinical practice careful attention must be given to the morphological changes, which have been well described and illustrated by Fairley and Birch. 1011

With careful instruction a receptive and intelligent junior technician with no qualifications can readily learn to differentiate glomerular from non-glomerular bleeding with a high degree of accuracy. An Adelaide group whose technician spent only a few hours with Dr Birch looking at the different types of glomerular and non-glomerular erythrocytes recently confirmed the accuracy of this method in distinguishing glomerular from non-glomerular disease. ${ }^{15}$

Many factors probably contribute to distort red cells as they pass down the tubule. Osmotic factors may alter their shape, and both stomatocytes and the cells resembling doughnuts typically seen in glomerular haematuria ${ }^{10}$ may be produced during slow-phase haemolysis. ${ }^{16}$ Phagocytosis of erythrocytes by renal tubular epithelium causes loss of haemoglobin and distortion of their shape; they may appear in the urine either free or within phagocytes. ${ }^{17}$

The best doctors do urine microscopy themselves and so may have the satisfaction of making a clear-cut diagnosis of glomerulonephritis directly after seeing a patient. The degree of the haematuria and other findings help to assess the need for further investigations including renal biopsy. The presence of oval fat bodies, proteinuria, and a modest rise in the urinary erythrocyte count suggests a diagnosis of membranous glomerulonephritis. ${ }^{10}$ If macroscopic haematuria or over $10^{9} \mathrm{red}$ cells/1 are found the biopsy specimen is very likely to show crescents. ${ }^{18} \mathrm{~A}$ modest rise in the glomerular red-cell count with no other abnormalities often reflects a mesangial proliferative lesion, but this is not always benign. ${ }^{8}$

Red cells are present in normal urine. Birch and Fairley found that these red cells are glomerular in type and that $95 \%$ of healthy people have a urinary erythrocyte count below $8 \times 10^{6} / 1{ }^{11}$ This contrasts with the figure of $1 \cdot 2 \times 10^{6} / 1$, which is derived from Addis's studies ${ }^{13}$ and which we confirm as the upper limit of normal using bright-field microscopy. This difference reflects the many dysmorphic red cells which are overlooked without the better definition given by phasecontrast microscopy. Electron microscopy confirms that these distorted and fragmented structures are indeed erythrocytes. ${ }^{11}$

Though early studies had documented casts in the urine after exercise, ${ }^{19-21}$ recent research has focused attention on the bladder as the source of exercise haematuria. Urologists have described lesions of the bladder ${ }^{22} 23$ and attribute haematuria after exercise to impaction of the flaccid posterior wall of the bladder against the base of the bladder during running. A study of marathon runners by Siegel et $a l^{24}$ has been widely quoted as further evidence that exercise haematuria is not renal. They found haematuria in nine of 50 men (all doctors) after a $42 \mathrm{~km}$ run but found no casts. On this basis they advised that patients should be spared expensive invasive testing for exercise-related haematuria but thought that the appearance of casts after running indicated the need for further investigations. Predictably this advice occasioned some comment from traditionalists, who advocate radiographic and endoscopic examination in all those who present with exerciserelated haematuria. ${ }^{25} \mathrm{~A}$ leading article ${ }^{1}$ in the $B M \mathcal{F}$ also took a conservative, cautious view.

A study ${ }^{27}$ using the new methods described above has recently reported the urine findings in 48 people before and after a long-distance run and has given results quite different from those of Siegel et al. ${ }^{24}$ Urine samples were examined by doctors and technicians experienced in interpreting redcell morphology, and they found an appreciable rise in the count of glomerular red cells in the urine in 44 of the 48 runners. Counts exceeded the normal range in 33; 46 showed an increase in hyaline and granular casts, and 10 showed red-cell casts after exercise. The red-cell morphology in all indicated a glomerular source for the haematuria.

The differences between these findings and those of Siegel et $a l^{24}$ are not easily explained. Many years ago Alyea and Parish $^{20}$ showed that the more prolonged the exercise the greater the urinary abnormalities, so the study by Siegel et al is puzzling in showing no casts after a $42 \mathrm{~km}$ marathon whereas casts were present in $95 \%$ of specimens after a 9 or $14 \mathrm{~km}$ run. We can assume only that the use of phase-contrast microscopy and quantitative counts explains the differences between the two studies (casts are much better defined by phase-contrast microscopy). ${ }^{26}$

These latest results seem to establish that the glomeruli are the usual source of haematuria after exercise. The abnormalities disappear within 24-48 hours, so they seem unlikely to give rise to cumulative damage as Alyea and Parish ${ }^{20}$ feared, and runners who present with this problem probably require no more than a careful examination of the urine repeated after 24-48 hours to provide the assurance that the abnormalities have indeed disappeared.

So where do the bladder lesions described by Blacklock ${ }^{22}$ and Fred and Natelson ${ }^{23}$ fit into the range of exercise-related haematuria? We have seen macroscopic haematuria and non-glomerular bleeding after strenuous exercise in two patients, one of whom had changes in the bladder due to chronic schistosomiasis. On present evidence bladder lesions seem likely to be present in only a very few of the runners who present with exercise-related haematuria-though such lesions may be more frequent among those who develop macroscopic bleeding.

\section{Priscilla Kincaid-SMith}

Professor of Medicine,

University of Melbourne, and

Director of Nephrology,

Royal Melbourne Hospital,

Victoria 3050,

Australia

${ }^{1}$ Anonymous. The haematuria of the long-distance runner. $\mathrm{Br} \mathrm{Med} \mathcal{F}$ 1979;ii:159.

${ }^{2}$ Carlton LE. The urologic examination and diagnostic techniques-initial evaluation including history, physical examination and urinalysis. In: Harrison HJ, Gittes RF, Perimutter AD, Stamey TA, Walsh PC, eds. Campbell's urology. Vol 1. 4th ed. Philadelphia: WB Saunders Co, $1979: 203-21$.

${ }^{3}$ Cole P, Monson RR, Haning H, Friedell GH. Smoking and cancer of the lower urinary tract. $N$ Engl $\mathcal{F}$ Med $1971 ; 284: 129-34$.

${ }^{4}$ Glen FJ. Renal tumors. In: Harrison HJ, Gittes RF, Perimutter AD, Stamey TA, Walsh PC, eds. Campbell's urology. Vol 2. 4th ed. Philadelphia: WB Saunders Co, 1979:967-1009.

${ }^{5}$ Vehaskari VM, Rapola J, Koskimies O, Savilahti E, Vilska J, Hallman N. Microscopic hematuria in schoolchildren: epidemiology and clinicopathologic evaluation. F Pediatr 1979;95:676-84.

${ }^{6}$ Larcom RC, Carter GH. Erythrocytes in urinary sediment: identification and normal limits. With a note on the nature of granular casts. $\mathcal{f} \mathrm{Lab}$ Clin Med 1948;33:875-80.

${ }^{7}$ Sinniah R, Pwee HS, Lim CH. Glomerulat lesions in asymptomatic microscopic hematuria discovered on routine medical examination. Clin Nephrol 1976;5:216-28.

${ }^{8}$ Pwee HS, Cheng Hong L, Sinniah R, Chiang G. Clinical course of asymptomatic haematuria/proteinuria. A three year study. $\mathcal{f}$ Med Assoc Thai $1978 ; 61$, suppl I:22-7.

${ }^{9}$ Birch DF, Fairley KF. Haematuria: glomerular or non-glomerular? Lancet 1979 ;ii :845-6.

${ }^{10}$ Fairley KF, Birch DF. Hematuria: a simple method for identifying glomerular bleeding. Kidney Int 1982;21:105-8.

${ }^{11}$ Birch DF, Fairley KF, Whitworth JA, et al. Urinary erythrocyte morphology in the diagnosis of glomerular haematuria. Submitted for publication. 
12 Jacobellis U, Fabiano A, Tallarigo C. A new technique to localize the origin of idiopathic microscopic hematuria. F Urol 1982;127:475-6.

13 Addis $T$. The number of formed elements in the urinary sediment of normal individuals. $\mathcal{f}$ Clin Invest 1926;2:409-15.

14 Addis T. Glomerular nephritis. New. York: MacMillan, 1948.

15 Fassett RG, Horgan BA, Mathew TH. Detection of glomerular bleeding by phase-contrast microscopy. Lancet $1982 ; \mathrm{i}: 1432-4$.

16 Chan TK, LaCelle PL, Weed RI. Slow phase hemolysis in hypotonic electrolyte solutions. $\mathcal{f}$ Cell Physiol 1975;85:47-57.

17 Kincaid-Smith P, Bennett WM, Dowling JP, Ryan GB. Acute renal failure and tubular necrosis associated with hematuria due to glomerulonephritis. Clin Nephrol (in press).

18 Bennett WM, Kincaid-Smith P. Macroscopic haematuria in mesangial IgA nephropathy: clinico-pathelogic correlations. Aust NZ $\mathcal{f}$ Med (in press).

19 Barach. JH. Physiological and pathological effects of severe exertion (the Marathon Race) on the circulatory and renal systems. Arch Intern Med $1910 ; 5: 382-405$.

${ }^{20}$ Alyea EP, Parish $\mathrm{HH}$. Renal response to exercise-urinary findings. FAMA 1958;167:807-13.

21 Gardner KD. "Athletic pseudonephritis"-alteration of urine sediment by athletic competition. $\mathcal{F} A M A 1956 ; 161: 1613-7$.

22 Blacklock NJ. Bladder trauma in the long-distance runner: " 10,000 metres haematuria." Br F Urol 1977;49:129-32.

${ }^{23}$ Fred HL, Natelson EA. Grossly bloody urine of runners. South Med $\mathcal{F}$ 1977;70:1394-6.

${ }^{24}$ Siegel AJ, Hennekens CH, Solomon HS, Van Boeckel B. Exercise-related hematuria. Findings in a group of marathon runners. FAMA 1979; 241:391-2.

${ }^{25}$ Whisnant JD. Exercise-related hematuria. FAMA 1979;242:1610.

${ }^{26}$ Russo MA, Cockett ATK. Microscopic urinalysis with phase contrast microscopy. 7 Urol 1972;107:843-9.

27 Fassett RG, Owen JE, Fairley J, Birch DF, Fairley KF. Urinary red-cell morphology during exercise. $B r$ Med $\mathcal{F} 1982 ; 285: 1455-7$.

\section{Sensitivity to tartrazine}

Patients who are sensitive to aspirin may also be sensitive to tartrazine, a yellow dye used in medicines and foods. ${ }^{1}$ Symptoms of an allergic reaction (urticaria, rhinitis, or asthma) may occur after exposure to many chemicals used to colour, flavour, or preserve food and drugs, but tartrazine (F D \& C yellow No 5) is the colour most frequently incriminated. Intolerance to tartrazine was first reported in $1959,{ }^{2}$ and its part in the induction of intractable urticaria has been recognised since $1975 .^{3}$ Non-thrombocytopenic purpura is also reported to be due to hypersensitivity to tartrazine-which suggests the possibility that tartrazine may act as a hapten bound to the endothelial cells of small blood vessels.

Tartrazine is a coal-tar derivative with a similar chemical structure to the benzoates, other azo compounds, pyrazole compounds, and the hydroxyaromatic acids; which include salicylates. It shows relatively little protein binding in comparison with non-azo dyes ${ }^{4}$ and may require prior metabolism before it can induce an immune response. The azo group can be reduced in the intestine and liver ${ }^{5}$ - one of the several routes through which the compound could be conjugated to form a potentially antigenic hapten structure. ${ }^{6}$

Recent studies have shown that clinical hypersensitivity to tartrazine may be associated with a humoral immune response to part of the molecule-namely, its sulphophenyl antigenic determinants. ${ }^{7}$ The antibodies were of the immunoglobulin IgD class, which suggests that immunological mechanisms other than those usually concerned in drug and food allergy play a part in hypersensitivity responses to additives. Additional evidence suggests that the clinical symptoms of intolerance to acetylsalicylic acid and tartrazine are probably not mediated by antibodies of the IgE class. ${ }^{8}$ The important mechanism behind the observed adverse response to aspirin is thought to be inhibition of prostaglandin-synthesising enzymes $^{1011}$; and the sensitivity of patients showing abnormal reactions to acetylsalicylic acid extends to other non-steroidal anti-inflammatory drugs and correlates with the ability of the drug concerned to inhibit prostaglandin synthesis. ${ }^{12}$ Possibly both the generation and effector function of suppressor cells may be modulated by prostaglandin inhibitors. ${ }^{13}$ Though patients have similar pathological reactions to tartrazine and acetylsalicylic acid, however, no effect of tartrazine on inhibition of prostaglandin pathways has been observed, ${ }^{13 a}{ }^{13 b}$ indicating that different biological pathways are concerned.

In practical terms, depending on the test protocol followed, ${ }^{14-16}$ between $10 \%$ and $40 \%$ of patients sensitive to aspirin respond to tartrazine, with reactions ranging from systemic anaphylaxis and severe asthma to urticaria and mild rhinitis. Medical practitioners need to know which drugs contain this dye so that they do not prescribe them for their aspirin-sensitive patients.

The prevalence of tartrazine sensitivity is not known but figures of 1 in 10000 have been suggested ${ }^{17}$-remarkably low, given the exposure. Several cases have been reported where the only possible source was a soft drink, ${ }^{18}$ and other people may have been adversely affected by tartrazine in foods. The incidence of tartrazine sensitivity appears to be higher in asthmatic or allergic subjects than in the general population. ${ }^{19}$ Subjects hypersensitive to one substance tend to be allergic to a variety of substances, which again suggests a difference in the general regulation of immune responses. People sensitive to acetylsalicylic acid who are allergic to foods ${ }^{20}$ should avoid tartrazine as a food dye.

The mechanism of the adverse reaction to tartrazine is not known. Existing tests are largely of low predictive value, and new methods to detect such reactions need to be investigated. Further research is needed into basic mechanisms and, if feasible, the epidemiology of the conditions provoked by tartrazine and corresponding agents to provide reliable data on the number of allergic responses associated with them. Only then can the hazard of tartrazine be properly evaluated.

KlaRa Miller

Head of Immunotoxicology Department,

British Industrial Biological Research Association,

Carshalton,

Surrey SM5 4DS

${ }^{1}$ MacCara ME. Tartrazine: a potentially hazardous dye in Canadian drugs. Can Med Assoc 7 1982;126:910-4.

${ }^{2}$ Lockey SD. Allergic reactions due to F D and C yellow No 5, tartrazine, an aniline dye used as a colouring and identifying agent in various steroids. Ann Allergy 1959;17:719-21.

3 Settipane GA, Pudupakkam RK. Aspirin intolerance III. Subtypes, familial occurrence and cross-reactivity with tartrazine. $\mathcal{F}$ Allergy Clin Imminol $1975 ; 56: 215-21$.

4 Gangolli SD, Grasso P, Golberg L, Hooson J. Protein binding by food colourings in relation to the production of subcutaneous sarcoma. Food Cosmet Toxicol 1972;10:449-62.

${ }^{5}$ Jones R, Ryan AJ, Wright SE. The metabolism and excretion of tartrazine in the rat, rabbit and man. Food Cosmet Toxicol 1964;2:447-52.

${ }^{6}$ Roxon JJ, Ryan AJ, Wright SE. Enzymatic reduction of tartrazine by Proteus vulgaris from rats. Food Cosmet Toxicol 1967;5:645-56.

7 Weliky N, Heiner DC. Hypersensitivity to chemicals. Correlation of tartrazine hypersensitivity with characteristic serum IgD and IgE immune response patterns. Clin Allery 1980;10:375-94.

${ }^{8}$ Weltman JK, Szaro RP, Settipane GA. An analysis of the role of IgE in intolerance to aspirin and tartrazine. Allergy 1978;33:273-81.

10 Vane JR. Inhibition of prostaglandin synthesis as a mechanism of action for aspirin like drugs. Nature (New Biology) 1971 ;231:232-5.

11 Szczeklik A, Gryglewski RJ, Czerniawska-Mysik G. Relationship of inhibition of prostaglandin biosynthesis by analgesics to asthma attacks in aspirin-sensitive patients. Br Med F 1975;i:67-9.

12 Szczeklik A, Gryglewski RJ, Czerniawska-Mysik G, Zmuda A. Aspirininduced asthma. Hypersensitivity to fenoprofen and ibuprofen in 